\title{
CASE 2-2012: A 57-YEAR-OLD WOMAN WITH POST-TRANSPLANT LYMPHOPROLIFERATIVE DISORDER AFTER ALLOGENEIC STEM CELL TRANSPLANTATION FOR PRIMARY MYELOFIBROSIS
}

\author{
Milan Košt’ál', Pavel Žák ${ }^{1}$, Eva Vejražkovál, Melánie Cermanová1, Petra Bělohlávkovál, Alžběta Zavřelovál, \\ Filip Vrbackýl, Tomáš Rozkoš2, Markéta Nováa
}

Charles University in Prague, Faculty of Medicine and University Hospital Hradec Králové, Czech Republic: 4th Department of Internal Medicine ${ }^{1}$, and The Fingerland Department of Pathology ${ }^{2}$

Key words: Allogeneic haematopoietic stem cell transplantation (HSCT); Post-transplant lymphoproliferative disorder (PTLD); Epstein-Barr virus (EBV)

\section{Introduction}

Allogeneic haematopoietic stem cell transplantation (HSCT) has become a major life sustaining treatment for haematopoietic disorders, and it is the preferred treatment option for selected patients with idiopathic myelofibrosis. Still, it may be accompanied by various complications. Here, we present a case of Epstein-Barr virus (EBV) - associated post-transplant lymphoproliferative disorder (PTLD), i.e. an infection-induced malignant proliferation following HSCT.

\section{Clinical data}

A 44-year-old woman was first seen at the outpatient haematological clinic with mild anaemia and splenomegaly in 1997. Her personal history was unremarkable. On the basis of the presence of diffuse bone marrow fibrosis, and the absence of Philadelphia chromosome and bcr/abl rearrangement, she was diagnosed with primary myelofibrosis (PMF). There were characteristic changes in a peripheral blood smear (erythroblasts, immature myeloid cells, anisopoikilocytosis with teardrop erythrocytes). The patient was in low risk group and did not require any special treatment at that time.

After 11 years without therapy (2008), her anaemia progressed (haemoglobin $<100 \mathrm{~g} / \mathrm{l}$ ) and her spleen was significantly enlarged. Myelofibrosis was confirmed in trepanobiopsy, and her genetic analysis revealed 13q deletion but she was negative for JAK2 V617F mutation. Treatment with thalidomide and prednisone was started, and her haemoglobin grew till 2010 (100-110 g/l). Considering her age, allogeneic HSCT was recommended. There was an intermediate risk according to Lilla score and an intermediate 2 risk according to IPSS (1). An unrelated, fully HLA-matched donor was found.

Reduced intensity conditioning was used as a preparative regimen, consisting of fludarabine $30 \mathrm{mg} / \mathrm{m}^{2}$ (days -9 to -4 ), busulfan $4 \mathrm{mg} / \mathrm{kg} . \mathrm{d}$ (days -8 to -7 ) and thymoglobulin $2.5 \mathrm{mg} / \mathrm{kg}$.d (days -3 to -1 ). Allogeneic peripheral haematopoietic stem cells were transplanted (day 0); the dose of CD34 positive cells was $7.17 \times 10^{6} / \mathrm{kg}$ of the recipient's weight. Tacrolimus (from day 1 ) and mycophenolat mofetil (starting 4 hours after HSCT) were used as immunosuppressive therapy. Fever and mucositis started two days after HSCT. A combination of antibiotics (meropenem, vancomycin, amikacin), antimycotics (voriconazole) and acyclovir was used in severe neutropenia. Specimens of blood and urine were obtained for culture and remained sterile. General condition of the patient was then stabilized; de-escalation of antibiotics was possible one week later. The regeneration of haematopoiesis started 15 days after allogeneic HSCT. However, a significant granulocyte engraftment $\left(0.5 \times 10^{9} / 1\right)$ was delayed till 30 days after HSCT, while thrombocyte engraftment was never achieved and there was still only 97\% donor's chimerism one month after HSCT.

During the sixth week after HSCT, the patient deteriorated considerably; fever $\left(38^{\circ} \mathrm{C}\right)$ and malaise returned, and gastrointestinal symptoms (sub-ileus, pain, ascites, nausea and later watery diarrhoea) appeared. Blood cultures remained sterile. The stool was negative for ova, parasites, bacterial pathogens, and Clostridium difficile toxin. Colonoscopy (with mucosal biopsies) was performed but neither graft versus host disease nor cytomegalovirus infection was demonstrated. CT and sonography revealed hepatosplenomegaly, portal hypertension, ascites and retroperitoneal 
lymphadenopathy. In peripheral blood, atypical lympho-monocytoid cells were detected (Fig. 1). An extremely high viral load $\left(11.5 \times 10^{6} / \mathrm{ml} ; 288,460 / 10,000\right.$ cells $)$ was found by polymerase chain reaction (PCR) test for EBV DNA. The patient died of severe sepsis on the forty-second day after allogeneic HSCT.

\section{Pathological findings}

Macroscopically. numerous tumour lesions of the small bowel (up to $2 \mathrm{~cm}$ in diameter) were found, together with hepatosplenomegaly $(2500 \mathrm{~g} / 2180 \mathrm{~g})$, ascites $(1000 \mathrm{ml})$, dilated portosystemic anastomoses (oesophagus, pelvic region) and signs of haemorrhagic diathesis (bleeding into the skin and visceral organs and massive enterorrhagia). There was also lung oedema, hydrothorax and dilatation of the right heart ventricle.

Histology revealed lymphoma infiltration of the liver, spleen, bone marrow, lymph nodes (Fig. 2) and small intestine. This lymphoproliferation was diagnosed by immunohistochemistry and in situ hybridization (Fig. 3) as: PTLD - B cell non Hodgkin lymphoma, EBV-associated diffuse large B-cell lymphoma (DLBCL) non-GC subtype with anaplastic features.

\section{Discussion}

PTLD can occur both after solid organ transplantation and after HSCT. The incidence and timing of the diagnosis depend on the transplanted organ and on the immunosuppression used. It is more common after lung or bowel transplantation (incidence up to 10\%) (2-4). For

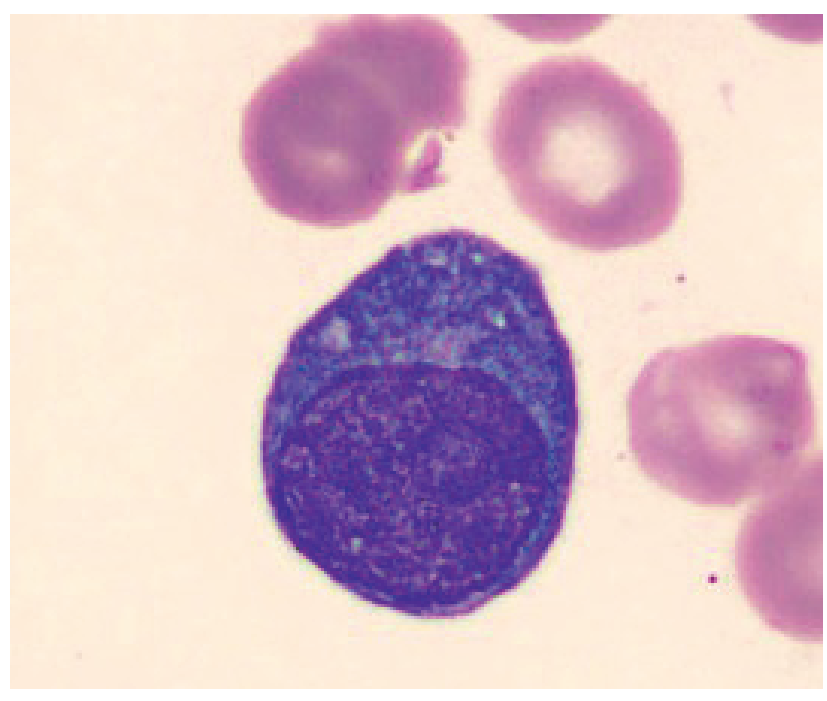

Fig. 1: Light microscopy: Lymfoplasmocytoid cell. May-Grünwald, Giemsa-Romanowski stain. Original magnification $100 \times$

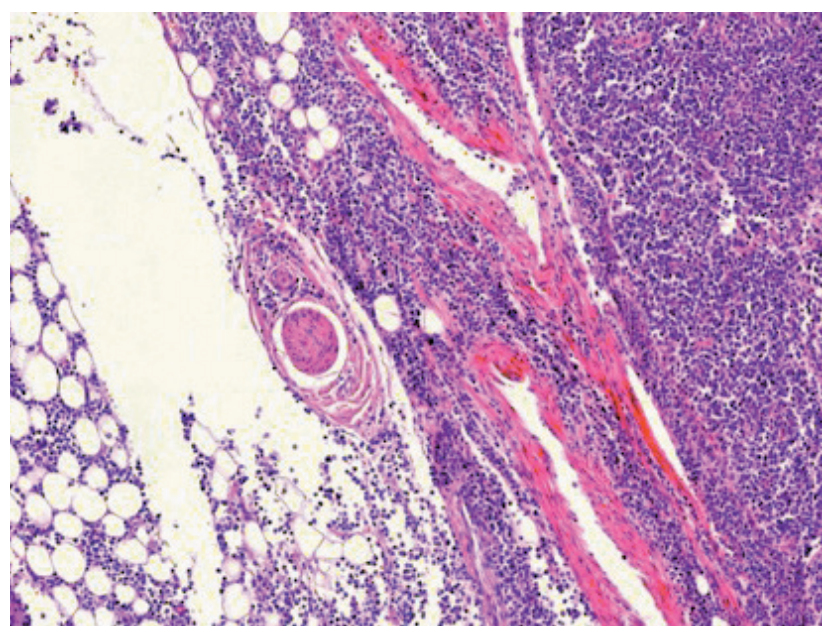

Fig. 2: Histology. Diffuse infiltration of the lymph node by lymphoma with infiltration through the capsule into the adjacent fat tissue. Haematoxylin-eosin staining. Original magnification $10 \times$

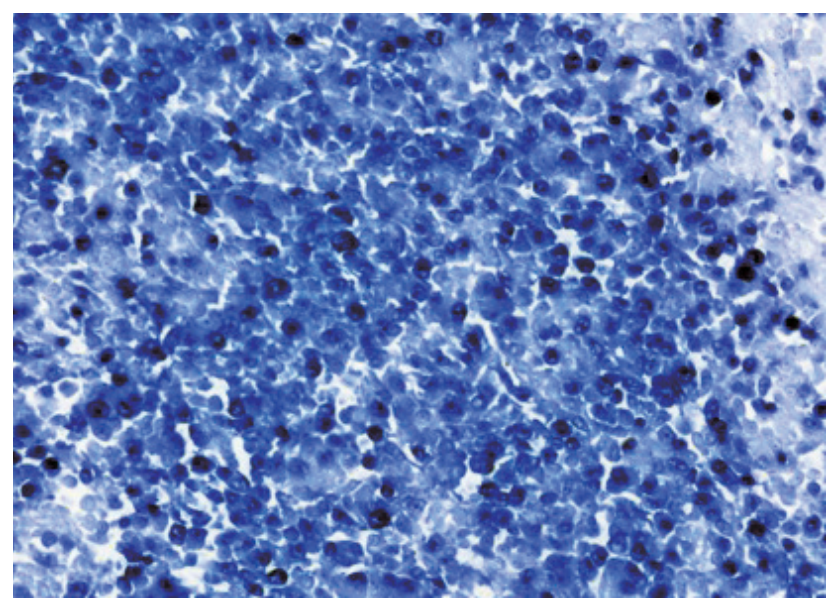

Fig. 3: Histology. Detection of the EBV encoded RNA (EBER) by in situ hybridization in the lymphoma cells (blue colour is positive). Original magnification $40 \times$

HSCT- associated PTLD, most cases are diagnosed within the first year after the transplantation (4). The disease is strongly associated with EBV infection (more than 80\%). The immunosuppressive treatment causes a depletion of EBV-specific cytotoxic T-lymphocytes that normally eliminate EBV-positive lymphocytes. These lymphocytes may then initiate cell growth dysfunction leading to PTLD. The role of other viral infections such as HTLV, human herpes virus 8 , cytomegalovirus, etc. remain unclear $(2,4,5)$. Cases of EBV-negative PTLD were also reported, and may represent a different entity (6). PTLD classification according to $\mathrm{WHO}$ is shown in Table 1. 
Tab. 1: WHO classification of post-transplant lymphoproliferative disorders (PTLD)

\begin{tabular}{|l|l|}
\hline Polyclonal lymphoproliferations & $\begin{array}{l}\text { Plasmacytic hyperplasia, infectious mononucleosis-like disease with involvement } \\
\text { of lymph nodes of Waldayer's ring. Biological character of these lesions is unclear, } \\
\text { they may represent reactive lesions. }\end{array}$ \\
\hline $\begin{array}{l}\text { Monoclonal } \\
\text { lymphoproliferations }\end{array}$ & $\begin{array}{l}\text { Polymorphic or monomorphic. Given the morphological and } \\
\text { immunohistochemical features, these lesions can be classified as malignant } \\
\text { lymphoma, most often represented by DLBCL. }\end{array}$ \\
\hline
\end{tabular}

Tab. 2: The most common EBV-associated lymphoproliferations

\begin{tabular}{|l|l|}
\hline B lymphomas & $\begin{array}{l}\text { Burkitt's lymphoma, Hodgkin's lymphoma, plasmablastic lymphoma, multiple } \\
\text { myeloma }\end{array}$ \\
\hline T lymphomas & angioimmunoblastic T lymphoma, nasal type of NK/T lymphoma \\
\hline
\end{tabular}

The most common EBV-associated lymphoproliferations are summarized in Table 2.

The symptoms of PTLD are variable and may include fever, enlargement of lymph nodes, weight loss, intestinal infiltration and septic shock. Extranodal manifestations (liver, lung, intestines, kidney, tonsil, bone marrow and skin) are common. Central nervous system involvement may be as high as $30 \%$, compared to only $1 \%$ in the non-transplanted population of non-Hodgkin lymphomas $(5,7)$.

EBV status is usually checked in both donor and recipient before HSCT because the risk for seronegative recipient in case of seropositive donor increases 10 to 50 fold (7). The quantity of EBV infection should be verified by real time PCR as in our case. Several clinical studies have reported a direct correlation between the EBV DNA load and the patient's clinical outcome $(2,4,5)$. Since there is a lack of data from clinical studies there is no firm recommendation concerning timing and frequency of EBV screening. The American Society of Transplantation recommends that all seronegative recipients should be screened monthly for EBV viral load in the first year following transplantation. EBV monitoring should be continued in patients with persistently higher copy number after the first year. The European Group for Blood and Marrow Transplantation recommends monitoring of EBV reactivation using quantitative PCR at least once a week for 3 months in high risk patients after allogeneic HSCT. All other indications for EBV monitoring depend on practice of the transplant centre (8).

When PTLD is considered, standard staging procedures (CT, PET, ultrasound) should be initiated, and aimed to the histological diagnosis. The treatment of PTLD is a complicated task. As the disease is quite rare, no standard recommendations exist. Therefore, the final decision should be made in cooperation of a transplant specialist and a haematooncologist experienced in lymphoma therapy (7). The treatment options in patients after allogeneic HSCT include approaches targeting malignant B-cells (e.g.
antiCD20 monoclonal antibody) or approaches reconstituting the immunity to EBV (e.g. EBV-specific cytotoxic T lymphocytes or donor lymphocyte infusion).

The treatment of PTLD can be started as a preemptive one. Preemptive therapy is defined as any agent or specific cells given to an asymptomatic patient with EBV detected by a screening essay. Today the most used preemptive and regular therapy includes anti-CD20 antibodies (Mabthera). The success rate of PTLD prevention using preemptive therapy is reported as high as $89 \%(4,9)$.

In our case, a standard allogeneic HSCT patient with an uncommon complication is reported. Both the donor and the recipient were seropositive in IgG class for EBV antibodies. Still, no EBV screening after transplantation was performed. The patient's non-specific symptoms were in keeping with neutropenia. Only late in the course of disease, the EBV screening was positive with high burden, and also lymphadenopathy was found. Clinically, the PTLD was considered but unfortunately no treatment or biopsy was possible due to a severe sepsis.

\section{Conclusion}

PTLD is an uncommon but severe complication of solid organ and haematological transplantations. The cell growth dysfunction leading to PTLD is closely related to EBV infection. Monitoring of EBV reactivation and preemptive treatment is recommended. Also our patient might have had a better prognosis if his EBV infection had been detected earlier and preemptive treatment started.

\section{Message from the Editor (Prof. Šteiner)}

Post-transplant lymphoproliferative disorders (PTLD) are lymphoid or plasmacytic proliferations that develop as a consequence of immunosuppression in a recipient of a solid organ, bone marrow or stem cell allograft (10). PTLD comprise a spectrum ranging from Epstein-Barr virus 
$(\mathrm{EBV})$ - driven infectious mononucleosis - type polyclonal proliferations to proliferations indistinguishable from B-cell or less often T-cell lymphomas that occur in immunocompetent individuals.

The most important risk factor for EBV - driven PTLD is EBV seronegativity at the time of transplantation. Among adult solid organ recipients, the frequency of PTLD ranges between $<1 \%$ and $5 \%$; in children, it is much higher. Peripheral blood, stem cell and bone marrow allograft recipients in general have a low risk of PTLD $(\sim 1 \%)$, with the risk higher e. g. with unrelated or HLA mismatched related donors.

The majority of PTLD is associated with EBV infection, and appears to represent EBV - induced monoclonal or, less often, polyclonal B-cell or monoclonal T-cell proliferations that occur in a setting of decreased T-cell immune surveillance. The organs most frequently involved are lymph nodes, gastrointestinal tract, lungs and liver. The mortality is greater in bone morrow allograft recipients than in solid organ allograft recipients.

The clinico-pathological conference has stressed the importance of monitoring of EBV reactivation and preemptive treatment in transplanted patients.

\section{Acknowledgement}

Supported by the programme PRVOUK P37/08.

\section{References}

1. Dupriez B, Morel P, et al. Prognostic factors in agnogenic myeloid metaplasia: report on 195 cases with a new scoring system. Blood. 1996; 88(3): 1013-83.

2. Aalto SM, Juvonen E, et al. Lymphoproliferative disease after allogeneic stem cell transplantation - pre-emptive diagnosis by quantification of Epstein-Barr virus DNA in serum. Journal of Clinical Virology: the official publication of the Pan American Society for Clinical Virology. 2003; 28(3): 275-83.

3. Baldanti F, Rognoni V, Cascina A, Oggionni T, Tinelli C, Meloni F. Post-transplant lymphoproliferative disorders and Epstein-Barr virus DNAemia in a cohor of lung transplant recipients. Virology Journal. 2011; 8: 421.

4. Weinstock DM, Ambrossi GG, Brennan C, Kiehn TE, Jakubowski A. Preemptive diagnosis and treatment of Epstein-Barr virus-associated post transplant lymphoproliferative disorder after hematopoietic stem cell transplant: an approach in development. Bone Marrow Transplantation. 2006; 37(6): 539-46.

5. Styczynski J, Einsele H, Gil L, Ljungman P. Outcome of treatment of EpsteinBarr virus-related post-transplant lymphoproliferative disorder in hematopoietic stem cell recipients: a comprehensive review of reported cases. Transplant Infectious Disease: an official journal of the Transplantation Society. 2009; 11(5): 383-92.

6. Nelson BP, Nalesnik MA, Bahler DW, Locker J, Fung JJ, Swerdlow SH. EpsteinBarr virus-negative post-transplant lymphoproliferative disorders: a distinct entity? The American Journal of Surgical Pathology. 2000; 24(3): 375-85.

7. Vegso G, Hajdu M, Sebestyen A. Lymphoproliferative disorders after solid organ transplantation-classification, incidence, risk factors, early detection and treatment options. Pathology Oncology Research: POR. 2011; 17(3): 443-54.

8. Humar A, Michaels M. American Society of Transplantation recommendations for screening, monitoring and reporting of infectious complications in immunosuppression trials in recipients of organ transplantation. American Journal of Transplantation: official journal of the American Society of Transplantation and the American Society of Transplant Surgeons. 2006; 6(2): 262-74

9. van Esser JW, Niesters HG, et al. Prevention of Epstein-Barr virus-lymphoproliferative disease by molecular monitoring and preemptive rituximab in high-risk patients after allogeneic stem cell transplantation. Blood. 2002; 99(12): 4364-9.

10. WHO Classification of Tumors of Haematopoietic and Lymphoid Tissues, 4th Edition. Ed. by Swerdlow SH, Campo E, Harris NL, et al., IARC, Lyon, 2008, $343-349$

\section{Corresponding author:}

Milan Košt’ál, MD, Department of Medicine IV, University Hospital, Sokolská 581, 50005 Hradec Králové, Czech Republic; e-mail: kosmil@seznam.cz 